\title{
Three novel trehalase genes from Harmonia axyridis (Coleoptera: Coccinellidae): cloning and regulation in response to rapid cold and re-warming
}

\author{
Zuo-Kun Shi ${ }^{1,2} \cdot$ Shi-Gui Wang ${ }^{2} \cdot$ Ting Zhang $^{1} \cdot \mathrm{Yu} \mathrm{Cao}^{1} \cdot \mathrm{Yan} \mathrm{Li}^{2} \cdot \mathrm{Can} \mathrm{Li}^{1}$
}

Received: 30 April 2019 / Accepted: 16 July 2019 / Published online: 6 August 2019

(c) The Author(s) 2019

\begin{abstract}
Trehalose is the main blood sugar in insects. To study the function of trehalase during exposure to low temperatures, three other novel cDNAs of trehalase were cloned from Harmonia axyridis by transcriptome sequencing and rapid amplification of cDNA ends. One of the cloned cDNAs encoded a soluble trehalase, the second trehalase cDNA encoded a transmembranelike domain, and the third cDNA encoded a membrane-bound protein. Therefore, these cDNAs were, respectively, named HaTreh1-5, HaTreh2-like, and HaTreh2. HaTreh1-5, HaTreh2-like, and HaTreh2 cDNAs encoded proteins containing 586, 553, and 633 amino acids with predicted masses of approximately 69.47, 63.46, and $73.66 \mathrm{kDa}$, and pIs of 9.20, 5.52, and 6.31, respectively. All three novel trehalases contained signal motifs "PGGINKESYYLDSY", "QWDYPNAWPP", and a highly conserved glycine-rich (GGGGEY) region. The expression levels of HaTreh1-5 and HaTreh2 mRNAs were high during adult stages, whereas HaTreh2-like was expressed in low amounts in the fourth larval stage. The results showed that the activity of membrane-bound trehalases decreased from 25 to $10^{\circ} \mathrm{C}$ and from 5 to $-5^{\circ} \mathrm{C}$ during cooling. The results also revealed a decreasing trend in expression of the three HaTreh mRNAs during the cooling treatment, and an initial decrease followed by an increase during the process of re-warming.
\end{abstract}

Keywords Harmonia axyridis $\cdot$ Membrane-bound trehalase $\cdot$ Rapid cold hardening $\cdot$ Soluble trehalase $\cdot$ Trehalose

\section{Introduction}

The disaccharide trehalose consists of two glucose units linked through an $\alpha$-glycosidic bond, which can synthesize in insect fat body by trehalose-6-phosphate synthase (TPS) and trehalose phosphate phosphatase (TPP) pathway (Caner et al. 2013; Tang et al. 2010; van Wyk et al. 2017; Xu et al.

Electronic supplementary material The online version of this article (https://doi.org/10.1007/s13205-019-1839-9) contains supplementary material, which is available to authorized users.

Can $\mathrm{Li}$

lican790108@163.com

1 Guizhou Provincial Key Laboratory for Rare Animal and Economic Insect of the Mountainous Region, Department of Biology and Engineering of Environment, Guiyang University, Guiyang 550005, People's Republic of China

2 College of Life and Environmental Sciences, Hangzhou Normal University, Hangzhou 310036, Zhejiang, People's Republic of China
2009; Yang et al. 2017; Tang et al. 2018). To our knowledge, trehalose is the main sugar in the hemolymph of insects, and exists in all kinds of organisms, except mammals. Its function is very important in insects and fungi (Elbein et al. 2003; Frison et al. 2007; Silva et al. 2010; Wingler 2002; $\mathrm{Xu}$ et al. 2009; Tang et al. 2018). Trehalose can be stored as energy and carbohydrates, and it is an agent that protects proteins and cell membranes from various environmental stress conditions, including desiccation, heat, freezing, and oxidation (Caner et al. 2013; Crowe et al. 1984; Eleutherio et al. 1993; Koštál et al. 2014). However, the detailed mechanisms of how trehalose protects insects from cold are still poorly understood, and little information about its effects under rapid cold or re-warming is present. To utilize blood trehalose, insect tissues have trehalases (alpha-glucoside1-glucohydrolase, EC 3.2.1.28) that catalyze the hydrolysis of one mole of trehalose to two moles of glucose (Silva et al. 2004; Thompson 2003; Shukla et al. 2019; Adhav et al. 2019). Trehalases are thought to be located on the cell membrane or within the cell cytoplasm (Valaitis and Bowers 1993; Yaginuma et al. 1996; Nardelli et al. 2019). 
The first study on soluble trehalase in insects involved the purification and assessment of some properties of this enzyme, including genetic and biochemical aspects, in Drosophila melanogaster. Only one molecular form of trehalase (E.C. 3.2.1.28) was detectable in adult $D$. melanogaster by polyacrylamide gel electrophoresis and isoelectric focusing (Bargiello and Grossfield 1980; Huber and Lefebvre 1971; Oliver et al. 1978). The first insect trehalase cDNA, a soluble trehalase, was cloned and reported in 1992 from Tenebrio molitor (Takiguchi et al. 1992). Although insects were divided into two types of trehalases, soluble (named Treh1, Tre1 or TreS) and membrane-bound (named Treh2, Tre2 or TreM) depending on whether they have potential putative transmembrane helices or domains, while Treh2 gene was not reported until 2005 (Mitsumasu et al. 2005). Treh2 possesses a transmembrane domain and is usually larger, whereas Treh1 lacks a transmembrane domain (Shukla et al. 2015). Treh1 is a cytosolic enzyme that hydrolyses endogenous trehalose, whereas Treh2 is an extracellular enzyme (Ma et al. 2015). Treh2 is believed to face the blood side, degrading the extracellular trehalose (Mitsumasu et al. 2005). The glucose so generated then enters into the cell and is utilized for physiological activities (Shukla et al. 2015). Moreover, most of the insect species, such as Spodoptera exigua (Chen et al. 2010; Tang et al. 2008), Apis mellifera (Lee et al. 2007; Mori et al. 2009), Bombyx mori (Kamei et al. 2011; Mitsumasu et al. 2005), Laodelphax striatellus (Zhang et al. 2012), Omphisa fuscidentalis (Tatun et al. 2008a, b), D. melanogaster (Shukla et al. 2016), Chironomus ramosus (Shukla et al. 2019), and others (Bansal et al. 2013), have genes for one soluble and one membrane-bound trehalase or only one of the trehalases. Two Trehl and one Treh2 genes have been cloned from Nilaparvata lugens $(\mathrm{Gu}$ et al. 2009; Zhao et al. 2016), four Trehl have been cloned from Harmonia axyridis (Shi et al. 2016; Tang et al. 2014), four Treh1 and one Treh2 have been cloned from Tribolium castaneum (Tang et al. 2016). However, not only two Treh1 and one Treh2, but also one Treh2-like have been cloned from Locusta migratoria (Liu et al. 2016), it is the firstreported insect to have a Treh2-like protein.

These trehalase genes have been cloned and studied in almost all the pests because of which they could be employed as potential target genes for insect control (Liebl et al. 2010; Zhao et al. 2016). Treh1 and Treh2 are known to regulate wing development, flight metabolism, and chitin biosynthesis, and they also play distinct roles in chitin biosynthesis and other physiological activities (Chen et al. 2010; Shukla et al. 2015). The beetle, Harmonia axyridis (Pallas), is an important natural enemy of pests, such as aphids, whiteflies, psyllids, mites, and the eggs and larvae of some lepidopterans and coleopterans (Luciana et al. 2015; Zappalà et al. 2013); it is the focus of pest control strategies in agriculture and forestry in Asia, including China (Tang et al. 2014), but is notorious for its invasiveness of the ecological niche of other ladybird beetles in Europe (Adriaens et al. 2008; Brown et al. 2008a, b). Cold hardiness and diapause are essential components of winter survival for most insects in temperate zones, but in many cases the relationship between these two are not clear (Heydari and Izadi 2014). The coldhardiness of $H$. axyridis represents an important characteristic and has been widely studied with respect to biological control applications and aspects of invasiveness (Bazzocchi et al. 2004; Berkvens et al. 2010; Pervez and Omkar 2006; van Lenteren et al. 2008). In addition, the genes controlling trehalase were identified as important to low-temperature stress resistance (Shi et al. 2016; Wu et al. 2016). Four soluble trehalase genes (HaTreh1-1 to HaTreh1-4) have been cloned (Shi et al. 2016; Tang et al. 2014). In the present study, a new soluble trehalase (HaTreh1-5), one membrane-bound (HaTreh2), and more importantly, one like membrane-bound trehalase (HaTreh2-like) cDNAs from $H$. axyridis were identified and cloned. The results obtained in this study can help understand the response of the trehalase gene to cold stress: (1) withstanding loss of activity at low temperature, (2) protecting cell function and thus surviving a sustained low-temperature exposure, or (3) repairing damage upon re-warming from a chill exposure.

\section{Materials and methods}

\section{Insect cultures}

Harmonia axyridis culture was established in our laboratory using insects collected from the Lab of Natural Enemy Research, Beijing Academy of Agriculture and Forestry Science. The experimental population was maintained in the laboratory at $25 \pm 1{ }^{\circ} \mathrm{C}$ for over 3 years and was fed Aphis medicaginis. The developmental stages were synchronized at each molt by collecting new larvae, pupae, or adult by giving fresh A. medicaginis, which were feeding on broad bean seedlings. The light period started at 06:00 $\mathrm{h}$ and ended at 22:00 h (L16:D8 photoperiod) (Shi et al. 2016).

\section{Cold and re-warming}

Heating and cooling rates really matter for insect survival (Terblanche et al. 2011). The expression of the genes was tested at six temperatures: $25^{\circ} \mathrm{C}, 15^{\circ} \mathrm{C}, 10{ }^{\circ} \mathrm{C}, 5^{\circ} \mathrm{C}, 0{ }^{\circ} \mathrm{C}$, and $-5{ }^{\circ} \mathrm{C}$. The choice of temperature refers to the study by Wang (Wang et al. 2017). To mimic the cooling conditions under natural conditions, we set a gradient of $5^{\circ} \mathrm{C}$ between -5 and $15^{\circ} \mathrm{C}$. Moreover, a previous study has shown that $5{ }^{\circ} \mathrm{C}$ may be the temperature signal of cold stress of $H$. axyridis (Shi et al. 2016). H. axyridis individuals were placed in one of the following environments with rapidly changing 
temperatures: (i) from 25 to $-5{ }^{\circ} \mathrm{C}$, or (ii) from -5 to $25^{\circ} \mathrm{C}$. The treatment (i) consisted of the following steps: one hundred and twenty individuals were placed in plastic fruit fly tubes sealed with sponge (ten individuals per tube) and were then maintained at $25^{\circ} \mathrm{C}$; after $2 \mathrm{~h}$ exposure to $25^{\circ} \mathrm{C}$, the tubes were cooled rapidly to $15^{\circ} \mathrm{C}$, and further cooled to $10{ }^{\circ} \mathrm{C}$ after $2 \mathrm{~h}$ exposure to $15^{\circ} \mathrm{C}$. Finally, the tubes were cooled to $-5{ }^{\circ} \mathrm{C}$; the treatment (ii) involved a similar procedure, but the starting temperature was set at $-5{ }^{\circ} \mathrm{C}$. The above treatments were repeated three times (Shi et al. 2016). The membrane-bound trehalase activities and gene expression levels were measured at each temperature.

\section{RNA extraction, CDNA synthesis, and rapid amplification of CDNA ends (RACE)}

Total RNA was extracted from adult individuals (with elytra removed) using the TRIzol (Invitrogen, USA) method. The first-strand cDNA synthesis was carried out according to the manual of PrimeScript ${ }^{\circledR}$ RT reagent Kit using gDNA Eraser (TaKaRa). The samples of $1 \mu \mathrm{g}$ total RNA were reversetranscribed at $42{ }^{\circ} \mathrm{C}$ for $1 \mathrm{~h}$ in a $10-\mu \mathrm{l}$ reaction mixture containing reaction buffer, $10 \mathrm{mM}$ DTT, $0.5 \mathrm{mM}$ dNTPs, $0.5 \mu \mathrm{g}$ oligo-dT18, and reverse transcriptase from avian myeloblastosis virus $(\mathrm{TaKaRa})$. First-strand cDNA $(1 \mu \mathrm{l})$ was used as a template for the polymerase chain reaction (PCR).

Partial sequences of the novel soluble and two membranebound trehalase genes were obtained by transcriptome sequencing of $H$. axyridis. Using 5'- and 3'-RACE, 5'-readycDNA and $3^{\prime}$-ready-cDNA were synthesized according to the manufacturer's protocol (SMART ${ }^{\mathrm{TM}}$ kit, TaKaRa). Specific primers, HaTreh2-like-5RA and HaTreh2-like-5RB for 5'-RACE and HaTreh1-5-3FA and HaTreh1-5-3FB, for 3'-RACE (Table 1), were synthesized based on the cDNA sequence obtained by transcriptome sequencing. 5'-RACE was performed using $2.5 \mu \mathrm{l}$ of $5^{\prime}$-ready-cDNA and Universal Primer Mix (UPM, TaKaRa) along with HaTreh1-5-5RA and HaTreh2-like-5RA, there after nested PCR was carried out with Nested Universal Primer A (NUP, TaKaRa) along with HaTreh1-5-5RB and HaTreh2-like-5RB. 3'-RACE was performed using $2.5 \mu \mathrm{l}$ of 3'-ready-cDNA and UPM along with HaTreh1-5-3FA and HaTreh2-like-3FA, followed by amplification using NUP along with HaTreh1-5-3FB and HaTreh2-like-3FB. The PCR conditions used were as follows: $10 \mathrm{~min}$ at $94{ }^{\circ} \mathrm{C}, 30$ cycles of $30 \mathrm{~s}$ at $94{ }^{\circ} \mathrm{C}, 30 \mathrm{~s}$ at $60{ }^{\circ} \mathrm{C}$, and $120 \mathrm{~s}$ at $72{ }^{\circ} \mathrm{C}$, followed by $10 \mathrm{~min}$ at $72{ }^{\circ} \mathrm{C}$.

The products were subjected to agarose gel electrophoresis. The desired DNA fragments were excised from the agarose gel and purified using a DNA gel extraction kit (OMEGA, USA). Purified DNA was ligated into pMD18-T vector (TaKaRa, Japan) and sequenced by dideoxynucleotide method.

\section{Analysis of the HaTreh CDNA and protein sequences}

HaTreh1-5 and HaTreh2 cDNA sequences were compared with other soluble and membrane-bound trehalase sequences present in GenBank using the BLAST-N and BLAST-X tools available on the National Center for Biotechnology Information (NCBI) website. Multiple sequence alignment of insect trehalases was performed using the tool available at the multiple sequence alignment website (http://bioin fo.genotoul.fr/multalin/multalin.html) and using Vector NTI Suite 9. The neighbor-joining method was used to construct a phylogenetic tree based on the amino acid sequences of known Treh proteins using MEGA 6.0 software. Bootstrap analysis was carried out and the robustness of each cluster was verified using 1000 replicates. HaTrehs protein sequences and other analysis criteria used in this study, including MW, pI, and topology were deduced from the
Table 1 The primers used in this study

\begin{tabular}{lll}
\hline PCR fragments & Primer names & Nucleotide sequences $\left(5^{\prime}-3^{\prime}\right)$ \\
\hline RACE & HaTreh1-5-3FA & CCTCCACTCCTCCTAATG \\
& HaTreh1-5-3FB & CCACACCAAGACCAGAGT \\
& HaTreh2-like-5RA & TCACATGCCGCTTTGATCTCCGAGT \\
& HaTreh2-like-5RB & GACCCTCTGAACTGTTACCATAA \\
QRT-PCR & HaTreh1-5QF & TGATGATGAGGTACGACGAGAA \\
& HaTreh1-5QR & GTAGCAAGGACCTAACAAACTGC \\
& HaTreh2-likeQF & TTCCAGGTGGGAGATTCAGG \\
& HaTreh2-likeQR & GGGATCAATGTAGGAGGCTGTG \\
& HaTreh2QF & CAATCAGGGTGCTGTAATGTCG \\
HaTreh2QR & CGTAGTTGGCTCATTCGTTTCC \\
Ha-rp49-QF & GCGATCGCTATGGAAAACTC \\
Ha-rp49-QR & TACGATTTTGCATCAACAGT \\
\hline
\end{tabular}

$\mathrm{F}$ and $\mathrm{R}$ represent forward and reverse primers, respectively Ha Harmonia axyridis, Treh trehalase 
corresponding cDNA sequences using the translation tool on the ExPASy proteome prediction tools website (http:// expasy.org/tools/dna.html). The analysis of HaTreh signal peptide was performed using "SignalP 4.1 server" available at http://www.cbs.dtu.dk/services/SignalP/.

\section{Expression level of HaTrehs during developmental stages, cooling and re-warming by quantitative real-time polymerase chain reaction (qRT-PCR)}

Total RNA was isolated from $H$. axyridis whole body (with elytra removed) on each day of its life cycle, including the fourth instar larvae, pupal, and adult (removal of elytra) stages, as well as total RNA was isolated from the entire body of $H$. axyridis (with elytra removed) during cooling and re-warming treatments. One microgram of total RNA was used as a template to synthesize first-strand cDNA using a PrimeScript RT with gDNA Eraser kit (TaKaRa, Japan). The expression of HaTreh1-5, HaTreh2-like, and HaTreh2 was estimated by qRT-PCR (Suann et al. 2015) using a BioRad CFX96 ${ }^{\mathrm{TM}}$ system (Bio-Rad, USA) and SsFast ${ }^{\mathrm{TM}}$ EvaGreen Supermix (Bio-Rad, USA). Primers were designed to determine the expression of the genes, HaTreh1-5, HaTreh2like, and HaTreh2 (Table 1). These primers were designed for their own unique regions found in the alignment using Vector NTI Suite 7. Each reaction was performed in a final volume of $20 \mu \mathrm{l}$, containing $1 \mu \mathrm{l}$ of the cDNA sample (or standard), $1 \mu \mathrm{l}(10 \mu \mathrm{M})$ of each primer, $7 \mu \mathrm{l}$ RNAase- and DNAase-free water, and $10 \mu \mathrm{l}$ of SsoFast ${ }^{\mathrm{TM}}$ EvaGreen Supermix. The cycling conditions consisted of $3 \mathrm{~min}$ of initial denaturation at $95^{\circ} \mathrm{C}, 40$ cycles of denaturation at $95{ }^{\circ} \mathrm{C}$ for $5 \mathrm{~s}$, annealing at $55^{\circ} \mathrm{C}-62.5^{\circ} \mathrm{C}$ for $20 \mathrm{~s}$, and finally a melt curve was made at $65-95^{\circ} \mathrm{C}$, as per the manufacturer's instructions.

The expression patterns of HaTreh1-5 and HaTreh2s mRNAs on each day of the life cycle of $H$. axyridis, from the fourth instar larva through pupa to 3-day-old adult, were determined by real-time quantitative PCR. Also the changes of HaTrehs expression level during cooling and re-warming were determined by qRT-PCR. The expression of $H$. axyridis rp49 (ribosomal protein 49 gene) on each day was used to standardize the relative expression levels of these three Treh genes (Shi et al. 2016).

\section{Activity assay for membrane-bound trehalase}

To determine the activity of trehalase, the extraction solution, containing membrane-bound trehalase, was reacted, in a $\mathrm{pH} 6.0$ buffer with excess substrates, by incubating at $37^{\circ} \mathrm{C}$ (Tatun et al. 2008a, b). Specifically, the whole body of three to five adults (with elytra removed), including male and female individuals, were homogenized in a 1.5-ml tube at $0{ }^{\circ} \mathrm{C}$ (TGrinder OSE-Y20 homogenizer, TIANGEN,
China) after adding $200 \mu \mathrm{l}$ of $20 \mathrm{mM}$ phosphate-buffered saline (PBS, pH 6.0), followed by sonication for $30 \mathrm{~s}$ (VCX $130 \mathrm{~PB}$, Sonics, USA). The homogenates were centrifuged at $1000 \times g$ at $4{ }^{\circ} \mathrm{C}$ for $10 \mathrm{~min}$ after adding $800 \mu \mathrm{PBS}$; the cuticle debris was removed and centrifuged at $105,000 \times g$ for $60 \mathrm{~min}$ at $4{ }^{\circ} \mathrm{C}$ (CP100MX, Hitachi, Japan). The supernatant was directly removed and the precipitate fraction was washed twice with PBS, and then suspended in $200 \mu \mathrm{PBS}$ for the measurement of membrane-bound trehalase. The amount of protein in each sample was determined prior to the trehalase assay by a protein-dye binding method (BioRad, USA) using bovine serum albumin as standard. The reaction mixture $(250 \mu \mathrm{l})$ for the membrane-bound trehalase activity assay, consisted of $62.5 \mu \mathrm{l} 40 \mathrm{mM}$ trehalose (Sigma, USA) in $20 \mathrm{mM}$ PBS (pH 6.0), $50 \mu 1$ membranebound trehalase extracts, and $137.5 \mu \mathrm{l}$ PBS. The mixture was incubated at $37^{\circ} \mathrm{C}$ for $30 \mathrm{~min}$, and the reaction was stopped by heating the reaction mixture in boiling water for $5 \mathrm{~min}$. Coagulated protein was removed by centrifugation at $12,000 \times g$ at $4{ }^{\circ} \mathrm{C}$ for $10 \mathrm{~min}$, and an aliquot of the resulting supernatant was used to measure the amount of glucose using a Glucose Assay Kit (GAGO20-1KT, Sigma, USA), following the manufacturer's instructions. First, glucose was converted into glucose acid and hydrogen peroxide in the presence of glucose oxidase; thereafter, hydrogen peroxide and $o$-dianisidine formed a colored product and finally, oxidic $o$-dianisidine reacted with sulfuric acid to form a more stable pink product, which was measured at $540 \mathrm{~nm}$. The membrane-bound activities were expressed as $\mathrm{mg}$ glucose/g protein/min.

\section{Statistical analysis}

Quantitative real-time PCR results were analyzed using a relative quantitative method $\left(\Delta \Delta \mathrm{C}_{\mathrm{t}}\right)$ (Livak and Schmittgen 2001). Standard curves were obtained using a tenfold serial dilution of pooled total RNA. All the data were presented as the relative mRNA expression (mean $\pm \mathrm{SD}$ ). Data of membrane-bound trehalase activities and relative mRNA expression were evaluated for normality and homogeneity of variance. Trehalase activity and gene expression levels were analyzed using one-way ANOVA with Statistica 7.0 software. Multiple comparisons of the means were conducted using Tukey's test. Differences between the means were deemed to be significant at $P<0.05$.

\section{Results}

\section{Structure of HaTreh1-5 and HaTreh2 proteins}

These three Trehs were named HaTreh1-5 (KX349223), HaTreh2-like (KX349224), and HaTreh2 (KX349225). 
HaTreh1-5, HaTreh2-like, and HaTreh2 cDNAs had open reading frames of 1761, 1662, and $1902 \mathrm{bp}$, respectively. HaTreh 1-5 cDNA encoded a protein of 586 amino acids with a predicted mass of approximately $69.47 \mathrm{kDa}$ and a pI of 9.20 (Fig. S1A), whereas HaTreh2-like and HaTreh2 encoded proteins of 553 and 633 amino acids with predicted mass of approximately 63.46 and $73.66 \mathrm{kDa}$, and pIs of 5.52 and 6.31, respectively (Fig. S1B, C).

The three new HaTreh proteins contained two specific motifs; HaTreh1-5 and HaTreh2 had the same specific motif "PGGRFKEFYYWDSY," whereas HaTreh2-like contained "PGGRFREFYYEDTY." Moreover, the HaTreh2-like and HaTreh2 had the same specific motif "QWDYPNAWPP," whereas HaTreh1-5 had "QWDLPNAWPP." Besides these specific motifs, the three new trehalase proteins contained the highly conserved glycine-rich (GGGGEY) region (Fig. 1) (Tang et al. 2012). Alignment of the proteins from a few other insect Trehs revealed that Treh1s had some conserved motifs. It was observed that all the insect Treh1s had one of the highly conserved motifs, "DSK*FVD", "PGGRFK/RE*YYWDSYW", or "IIPVDLN", and also included "PRPESY" (Fig. 1a), Treh2s had "DSKT/ YFVDMK", "LGRKM", "PNGGR", and "WLDYD" motifs (Fig. 1b).

\section{Phylogenetic and multiple protein alignment analyses}

Some of the insect soluble and membrane-bound trehalase proteins were employed for phylogenetic analysis using MEGA6.0 software. The results showed that Treh1 and Treh2 proteins could be easily distinguished and that trehalases from the coleopteran insects could be assigned to the same subgroup (Fig. 2). H. axyridis and T. castaneum had five soluble trehalase proteins, and T. molitor had two soluble trehalases; twelve trehalases could be assigned to the same subgroup. The other soluble trehalases assigned to this subgroup, included trehalase of Escherichia coli, which formed a single member out-group. The membrane-bound trehalase proteins were assigned to another subgroup that excluded HaTreh2-like, which formed a single subgroup (Fig. 2). However, HaTreh2-like did not have the transmembrane domain near the $\mathrm{C}$ terminus and only have a transmembrane-like domain, but it was very similar to the other insect Treh proteins, especially HaTreh2 (Fig. 1b); therefore, it was named HaTreh2-like. We found a total of five trehalases in H. axyridis, namely HaTreh1-1, HaTreh1-2, HaTreh1-3, HaTreh1-4, and HaTreh1-5; all these belonged to the soluble trehalase cluster and were associated with TmTreh and TcTreh1.

HaTreh1-5, HaTreh2-like, and HaTreh2, showed $30.30-50.27,31.57-51.37$, and $32.77-65.66 \%$ identity to the other known Treh family genes. The soluble trehalase
Trehl family could be clearly distinguished from the membrane-bound trehalase forms from different insects (Fig. 1). HaTreh2-like and HaTreh2 had the lowest identity with HaTreh1-3, which was 31.57 and $32.77 \%$, respectively, and was even lower than the E. coli Treh protein (Table 2). HaTreh2-like had the highest identity of $51.37 \%$ with HaTreh2; it also had a higher identity with Treh2 than with Treh1 in the same insect. HaTreh1-5 was most identical to HaTreh1-like (50.27\% identity) and TmTreh1-2 (50.50\% identity), HaTreh2-like was most identical to HaTreh2 (51.37\% identity) and TcTreh2 (50.82\% identity), whereas HaTreh2 was most identical to TcTreh2 (65.66\% identity) and LsTreh2 (58.63\% identity) (Table 2).

\section{Developmental expression pattern of HaTreh 1-5 and HaTreh2s}

The expression of HaTrehl-5 was different during the different developmental stages. It increased from the first to the fourth day during the fourth larval stage, and decreased from the first to the third day in the pupal stages; the expression was higher during the previous 3 days of the adults (Fig. 3). The results showed that the expression of HaTreh2like genes was at low level during the fourth larval stages and it reached the highest level at pre-pupae stage, and was followed by a decrease from the pre-pupal stage to the third day of pupa (Fig. 3). A uniform expression was observed during the 3 days of the adult stage. Although the expression pattern of HaTreh2 was different from that of HaTreh1-5 and HaTreh2-like genes, it had relatively lower expression levels from the first day of fourth instar larvae to the third day of pupal stage, and higher expression levels were observed during the adult stages (Fig. 3). Moreover, the expression of HaTreh2-like was higher in the pre-pupal stage whereas that of HaTreh2 was higher in the adult stages (Fig. 3).

\section{Effects of cooling and re-warming process on the membrane-bound trehalase activity}

Significant differences were observed in the activity of membrane-bound trehalases under the environments that were cooled or warmed. In the environment cooled from 25 to $-5^{\circ} \mathrm{C}$, the activity decreased in two steps, from 25 to $10^{\circ} \mathrm{C}$ and from 5 to $-5{ }^{\circ} \mathrm{C}$; the activity was higher at 25 and $5{ }^{\circ} \mathrm{C}$ than at 10,0 , and $-5^{\circ} \mathrm{C}$ (Fig. 4a). The Treh2 activity was increased from 10 to $5{ }^{\circ} \mathrm{C}$, it showed that more trehalose was needed for degradation to glucose for providing energy. In contrast, in the environment warmed from -5 to $25^{\circ} \mathrm{C}$, the enzyme activity increased compared to the activity at -5 and $0{ }^{\circ} \mathrm{C}$; the highest activity was observed at $5{ }^{\circ} \mathrm{C}$ (Fig. $4 \mathrm{~b}$ ). From 5 to $25^{\circ} \mathrm{C}$, the trehalase activity showed a relatively higher value compared to that at -5 and $0{ }^{\circ} \mathrm{C}$ (Fig. 4b). Both, under the cooling and warming environments, the 
Fig. 1 Alignment of Treh1 and Treh2 protein sequences from different insect species. a Alignment of HaTreh1-5 (KX349223), HaTreh1-2 (FJ501961), TmTreh1 (T. molitor, P32359), PmTreh1 (Papilio machaon, KPJ08342), AeTreh1 (Acromyrmex echinatior, EGI57245), and BhTreh1 (Bombus hypocrite, AHN15422) using Vector NTI 9.0 software. b Alignment of HaTreh2-like (KX349224), HaTreh2 (KX349225), AlTreh2 (Apolygus lucorum, AGL34007), LsTreh2 (L. striatellus, AFL03410), and TsTreh2 (Trachymyrmex septentrionalis, KYN38309) using Vector NTI 9.0 software. Highly conserved regions are shown in yellow and sky blue. Insect trehalase signatures and conserved sequences are boxed
A

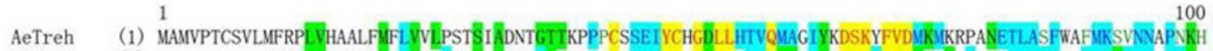
BhTreh

(utreh1-2

HaTreh1-2

Treh1-5

PmTreh

AeTreh

BhTreh

HaTreh1-2

HaTreh1-5

TmTreh

PmTreh

AeTreh

BhTreh

HaTreh1-2

HaTreh1-5

PmTreh

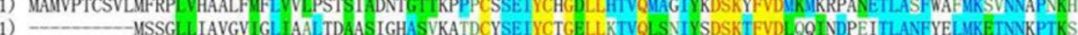

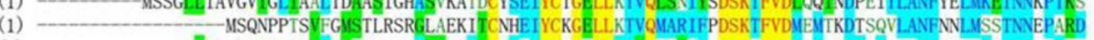

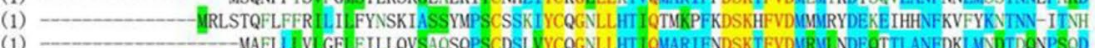

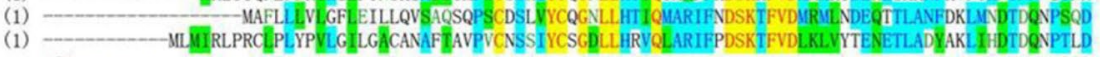

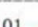

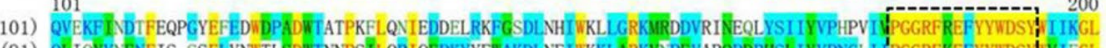

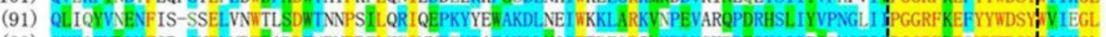
(83) QVKOFVDDNFQP-GNEL MDUEA EPDENPNPPFL KEIMVPEYRAFAKDL VOIVTDFSRIL KPDVSKEPERYSI IPISNGFI PGGRFREIYYWDSI IIIKGL,

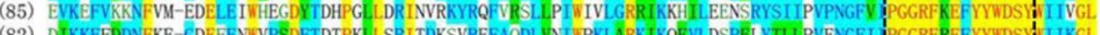

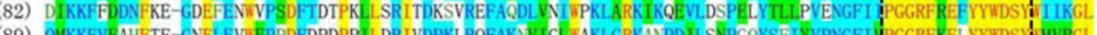
201

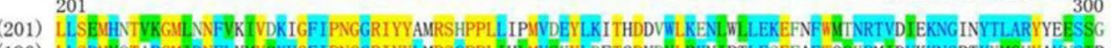
(190) LLSDUYQTARGMIDNFL YWVRYGFI PNGGRIYYLMRSQPPLL IHLIVSKYLDFTGDYDY RKVIPTLESEFAFWQQKRMIDVKKNGRTYKMGHYAVISIR

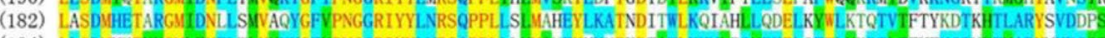

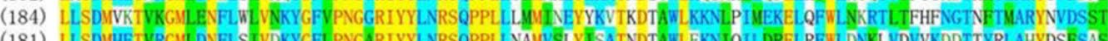

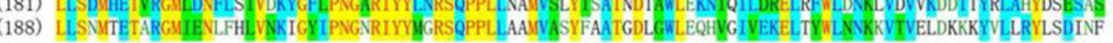
301

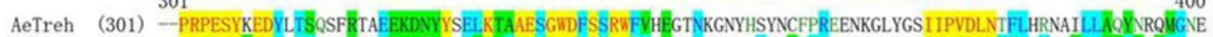

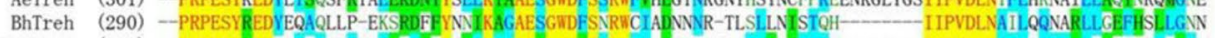

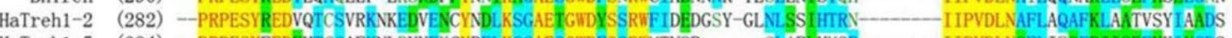
HaTreh1-5 (284) --PRPESYFEDEHICSAFKNLRVVEKCYRELKSGAESGWDFSSRMITNRR - - SLAEL VVSR-- - IIPVDLISFLIESFRIISEFYKIVGIS

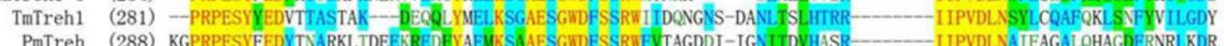

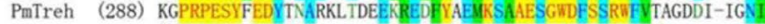

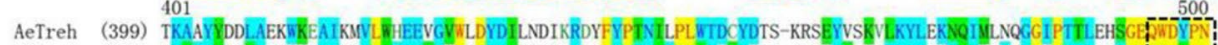

BhTreh (378) AKSOYYHKVASQLOMA IDNVL NNEEEGTHLDYDNKNEKPRHAFYPSNLAPLYTRSYYRL-QRKRYALSIVKYLKTQNIDTFLGGTPTSLNYTG G WWDEPN

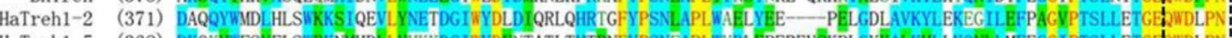

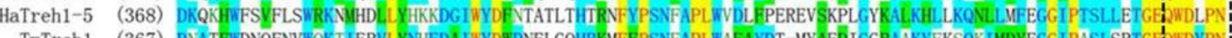

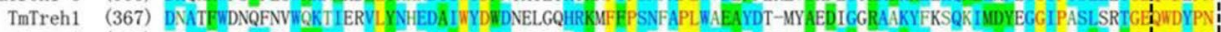

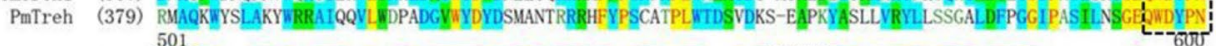

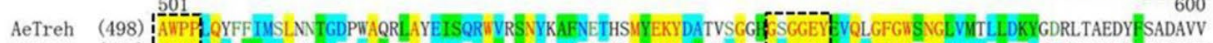

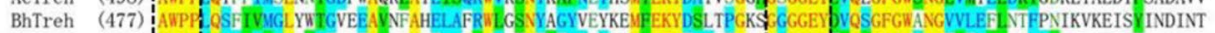

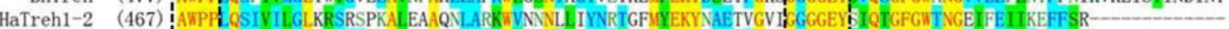

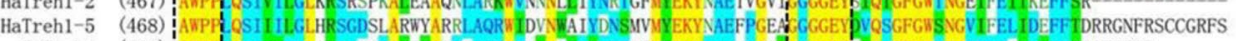

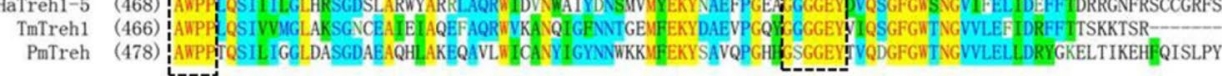

\section{B}

B AITreh (1) 1100 AmTreh (1) -MASSCSIRCGSRNILVWAAMATFLALIVVLRCFANAE-KPSPCQSDVYCRGELLHTIOUASIYKDSKTFVDMKUKRPPDETLKSSFREFUERHEQMPT

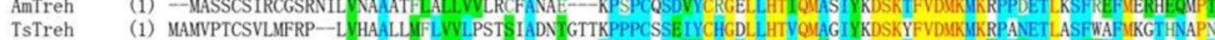

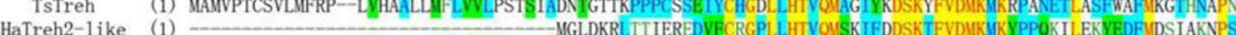

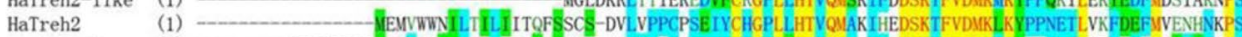

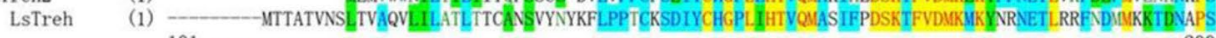
10

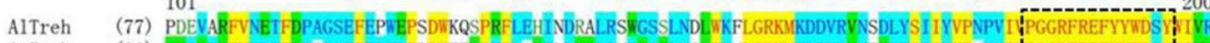
AmTreh (96) RYOIERFVDTFDPEGSEFEDWDPDDITFRPRFLSRILDDDLRNFASEL NG WKMLGRKIKDDVRVNEELIYSI IYVPHPVI I PGGRFREFYYWDSYHIVK

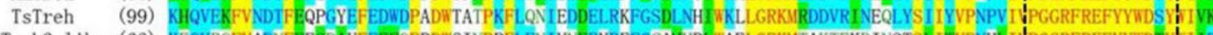

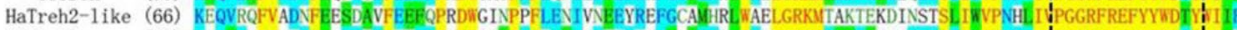

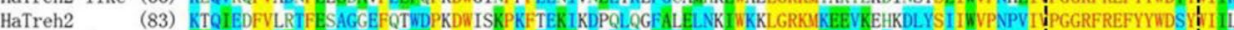

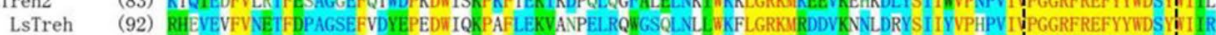

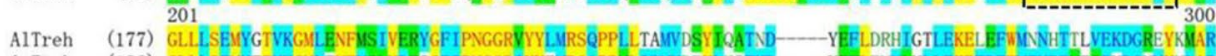

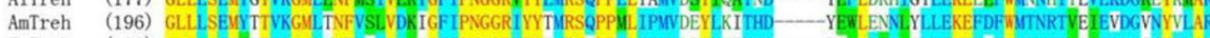

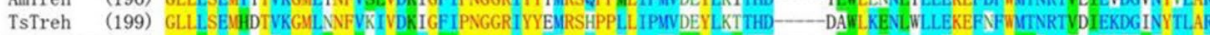
HaTreh2-1ike (166) GLLISEMYYETTKGMIDNFL HIVERYGYVPNGGRIYYLGRSQPPTL IPSFKAYLDAEDTSYTDHSDYL KKNIHLL SKEFDFW ISXRTTVVKLGDREYTLAI HaTreh2 (183) GLLLSEVVATTKGMLENFLYMVDVYGLIPNGGRYYYLERSQPPLLIPYIKLYYDSTND- KOFLKDNIRIMEKEFVYULTNHSVQVLLGGRYYTLAH LsTreh (192) GLLYSQUYYSTARGMIFNFVTIVDQYG GIPNGGRIYYAMRSQPPLLSPUVKSYLDVTHD- MQFLKDNINTLEKEFDFU INNRTTQVEKDGHMYTLAP

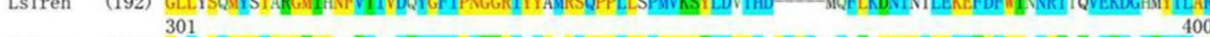

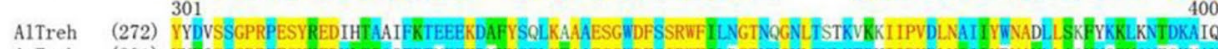
AmTreh (291) YNEQSSGPRPESYKEDYLTSQSFRTYEEKDYYYSELKTMAESGWDFSSRUF LLDGTNKGNLTNLKTRYIIPVDLISIYYRNAVVLLAOYNORUGNESKVAY TsTreh (294) YYEESSGPRPESYKEDYLTSQSFRTAEEKDVYYSEL KIAAESGMDFSSRWFVHEGINKGNLTNLKTRSI IPVDLNTFLYRNAILLAOYNROMGNETKAAH HaTreh2-1ike (266) YGVSSEGPRAESYAEDVESAAPLEGEEAKASFYSE IKAACESGMDFISRMFVSNGTSKGSLRDTKTTS IIPVDLNAILYNVAVILQEFYTRL SQFDRAAY HaTreh2 (278) YGURSHGPRPESYSEDVWSATYLNEAE-KESFYSELKAMAESGWOFSSRTF SNGTNAGNLTNMTRSIIPVDLNAIMYWNAKLLGDYNKILGDSDKAEY

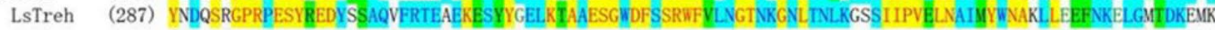

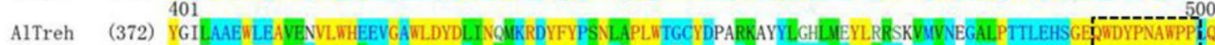

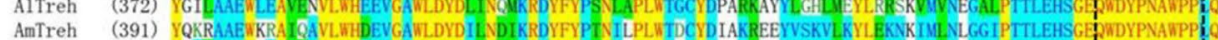

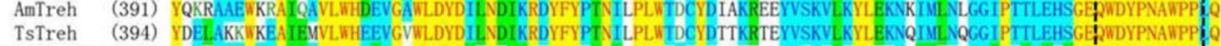

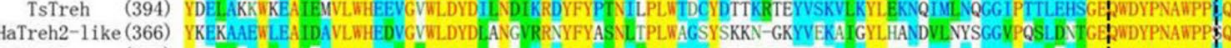

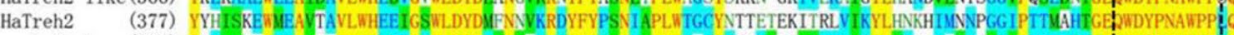

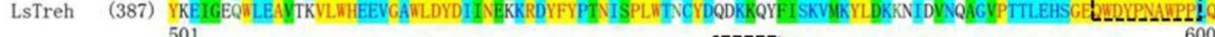

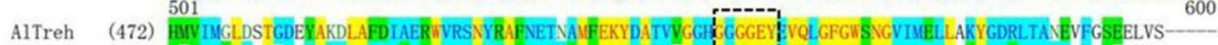

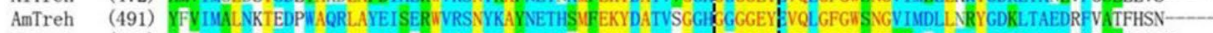

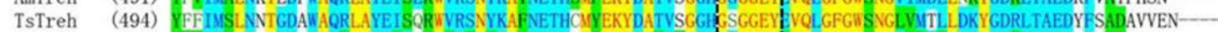

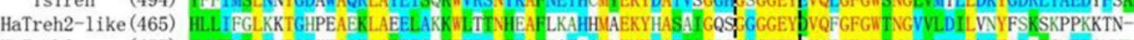

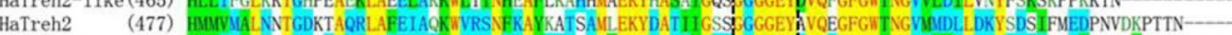

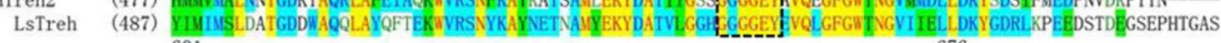

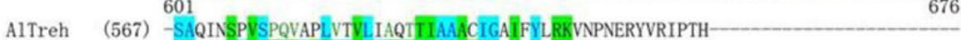

AmTreh (586) -STPQPVYVSTAGQWMTGILALVISLAAGFIGKMRCANXAAQ-

HaTreh2-1ike (554) -

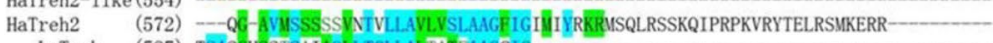

LsTreh (587) TSASGHSSISAIAOLLTGLLALTATFAAGCIG 
Fig. 2 Phylogenetic tree constructed using the amino acid sequences of some known soluble and membrane-bound insect trehalases. Full-length amino acid sequences were aligned using the Mega 6.0 program. A bootstrap analysis was carried out and the robustness of each cluster was verified using 1000 replicates. Values at the cluster branches indicate the results of the bootstrap analysis. The soluble trehalase family proteins were LsTreh1 and LsTreh2 (L. striatellus), AlTreh1 and AlTreh2 (Apolygus lucorum), SeTreh1 and SeTreh2 $(S$. exigua), OfTreh1 and OfTreh2 (O. fuscidentalis), TcTreh1s and TcTreh2 (T. castaneum), NITreh1s and N1Treh2 (N. lugens), SfTreh1 and SfTreh2 (Spodoptera frugiperda), TmTreh1s (T. molitor), and EcTreh (E. coli). 1-1, 1-2, 1-3, 1-4, and 1-5 show that the species has few of the different soluble trehalases. Characters in parentheses are the GenBank accession numbers

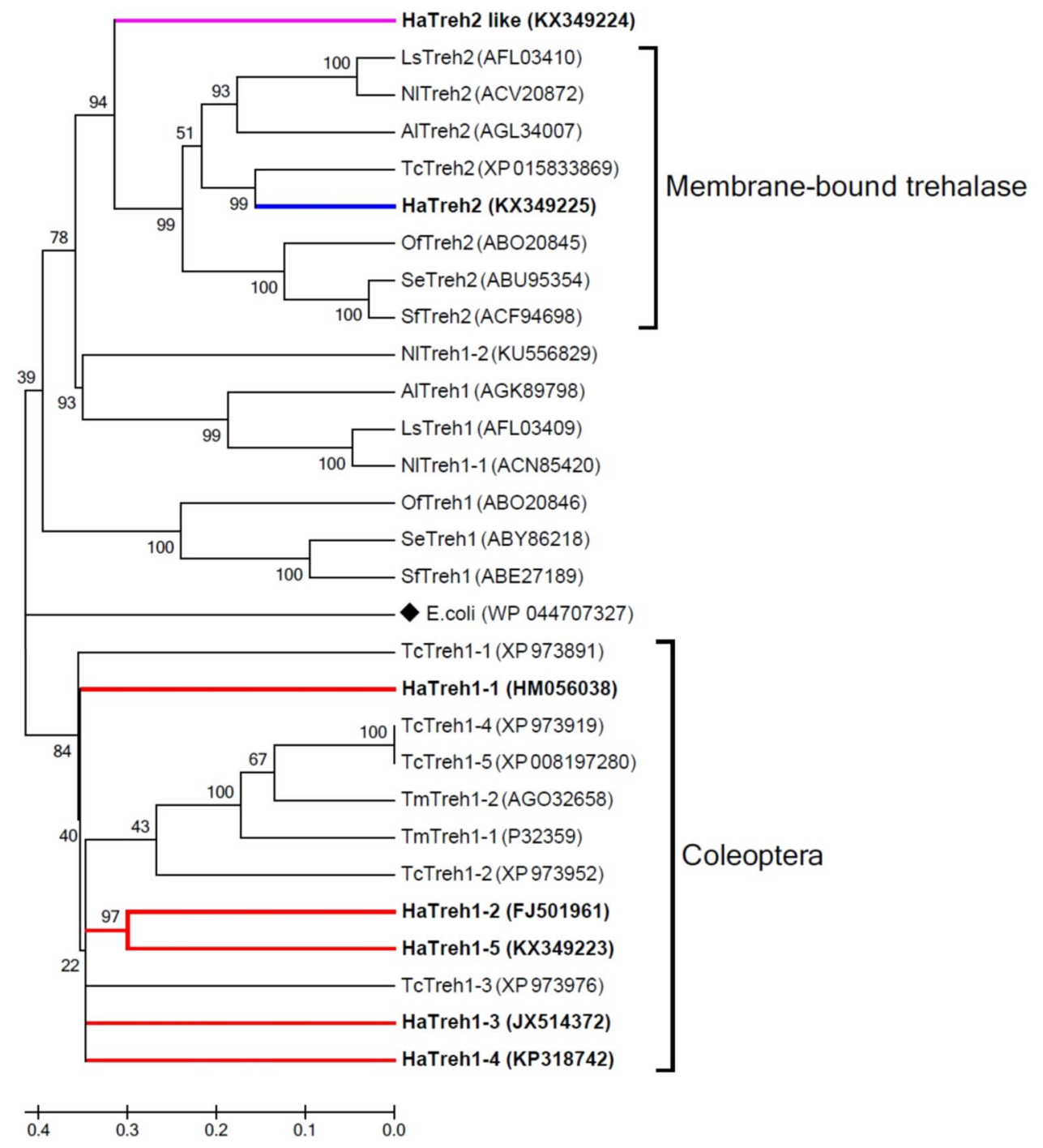

membrane-bound trehalase activity reached a maximum at $5^{\circ} \mathrm{C}$.

\section{Changes in the expression of three Treh mRNAs during rapid cold and re-warming treatment}

In the cooling treatment groups, the mRNA expression of HaTreh1-5, HaTreh2-like, and HaTreh2 decreased significantly from 25 to $-5{ }^{\circ} \mathrm{C}$, the expression of all the three genes being highest at $25^{\circ} \mathrm{C}$ (Fig. 5a, c, e). The expression of all the three genes was also higher at $5{ }^{\circ} \mathrm{C}$ compared to the expression at other treatment temperatures. The expression of HaTrehl-5 was very low at 10 and $-5{ }^{\circ} \mathrm{C}$ (Fig. 5a), whereas that of HaTreh2 was low at 10 and $0{ }^{\circ} \mathrm{C}$ (Fig. 5e); the expression of HaTreh2-like was low at all the temperatures except at 25 and $5{ }^{\circ} \mathrm{C}$ (Fig. 5c). The expression patterns of the three genes were different in the warming treatment groups. HaTreh1-5 and HaTreh2-like expression had a similar trend; it decreased first followed by an increase.
The expression of HaTreh1-5 was significantly lower at $5{ }^{\circ} \mathrm{C}$ than at other temperatures (Fig. 5b). The expression of HaTreh2-like was lowest at $15^{\circ} \mathrm{C}$ (Fig. 5d). The expression of HaTreh 2 increased from -5 to $25{ }^{\circ} \mathrm{C}$; it was high at 0 and $15^{\circ} \mathrm{C}$ and reached the highest level at $25^{\circ} \mathrm{C}$ (Fig. 5f).

\section{Discussion}

Insect trehalase proteins have the same or similar characteristic motifs ("PGGRFREFYYWDSY", "QWDYPNAWPP" and "GGGGEY"), which are essential for catalytic activity and substrate-binding functions (Mitsumasu et al. 2005; Shukla et al. 2015; Tang et al. 2008, 2012; Nardelli et al. 2019). All these features suggest that it is a relatively conserved protein family (Forcella et al. 2010). HaTreh1-3 showed low identity with HaTreh1-5 (35.12\%), HaTreh2like (31.57\%), and HaTreh2 (32.77\%) (Table 2), which could also be the reason for HaTreh1-3 being present on a separate

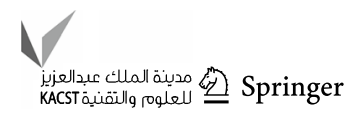


Table 2 The related information of Treh gene family and the identity (\%) to HaTreh1-5, HaTreh2-like and HaTreh2

\begin{tabular}{|c|c|c|c|c|c|c|}
\hline Gene names & Species & $\begin{array}{l}\text { Number of } \\
\text { amino acids }\end{array}$ & Genebank numbers & $\begin{array}{l}\text { Identity (\%) to } \\
\text { HaTreh1-5 }\end{array}$ & $\begin{array}{l}\text { Identity (\%) to } \\
\text { HaTreh2-like }\end{array}$ & $\begin{array}{l}\text { Identity (\%) } \\
\text { to HaTreh2 }\end{array}$ \\
\hline HaTreh1-1 & Harmonia axyridis & 554 & HM056038 & 44.71 & 41.79 & 44.33 \\
\hline HaTreh1-2 & H. axyridis & 553 & FJ501961 & 50.27 & 41.04 & 42.91 \\
\hline HaTreh1-3 & H. axyridis & 547 & JX514372 & 35.12 & 31.57 & 32.77 \\
\hline HaTreh1-4 & H. axyridis & 558 & KP318742 & 44.93 & 41.48 & 40.69 \\
\hline HaTreh1-5 & H. axyridis & 586 & KX349223 & - & 38.63 & 41.08 \\
\hline HaTreh2-like & H. axyridis & 553 & KX349224 & 38.63 & - & 51.37 \\
\hline HaTreh2 & H. axyridis & 633 & KX349225 & 41.08 & 51.37 & - \\
\hline TcTreh1-1 & Tribolium castaneum & 541 & XP973891 & 42.86 & 45.63 & 47.37 \\
\hline TcTreh1-2 & T. castaneum & 548 & XP973952 & 45.86 & 42.67 & 45.47 \\
\hline TcTren1-3 & T. castaneum & 563 & XP973976 & 44.78 & 42.86 & 43.76 \\
\hline TcTreh1-4 & T. castaneum & 553 & XР973919 & 48.99 & 45.27 & 47.24 \\
\hline TcTreh1-5 & T. castaneum & 585 & XР008197280 & 48.38 & 45.27 & 47.08 \\
\hline TcTreh2 & T. castaneum & 603 & XP015833869 & 40.63 & 50.82 & 65.66 \\
\hline TmTren1-1 & Tenebrio molitor & 555 & P32359 & 48.82 & 42.19 & 44.04 \\
\hline TmTreh1-2 & T. molitor & 558 & AGO32658 & 50.00 & 42.70 & 46.45 \\
\hline N1Treh1-1 & Nilaparvata lugens & 546 & ACN85420 & 40.30 & 43.39 & 43.58 \\
\hline NITreh1-2 & N. lugens & 501 & KU556829 & 37.85 & 38.04 & 40.64 \\
\hline N1Treh2 & N. lugens & 665 & ACV20872 & 40.38 & 48.26 & 55.40 \\
\hline LsTreh1 & Laodelphax striatellus & 602 & AFL03409 & 38.32 & 41.03 & 41.93 \\
\hline LsTreh2 & L. striatellus & 618 & AFL03410 & 39.93 & 49.27 & 58.63 \\
\hline AlTreh1 & Apolygus lucorum & 643 & AGK89798 & 39.54 & 43.75 & 50.49 \\
\hline AlTreh2 & A. lucorum & 617 & AGL34007 & 42.35 & 48.91 & 54.73 \\
\hline OfTreh1 & Omphisa fuscidentalis & 581 & ABO20846 & 40.00 & 41.47 & 43.78 \\
\hline OfTreh2 & O. fuscidentalis & 647 & ABO20845 & 37.79 & 48.08 & 55.29 \\
\hline SeTreh1 & Spodoptera exigua & 585 & ABY86218 & 36.63 & 39.08 & 41.83 \\
\hline SeTreh2 & S. exigua & 645 & ABU95354 & 37.39 & 47.99 & 55.56 \\
\hline SfTreh1 & Spodoptera frugiperda & 587 & ABE27189 & 36.68 & 39.82 & 42.56 \\
\hline SfTreh2 & S. frugiperda & 647 & ACF94698 & 36.87 & 47.81 & 55.39 \\
\hline EcTreh & Escherichia coli & 565 & WP_044707327 & 30.30 & 32.35 & 33.15 \\
\hline
\end{tabular}

branch in the Treh1 phylogenetic tree compared to the other Treh1s and for HaTreh 1-3 showing only 28-40\% identity to other known Trehl family genes (Tang et al. 2014). HaTreh1-1, HaTreh1-3, and HaTreh1-4 were present on a single branch in the phylogenetic tree (Fig. 2). They also possessed some other conserved motifs, including "PVD/ ELN" and "PRPESY" (Fig. 1), similar to the other HaTreh1s (Tang et al. 2014). Moreover, most of the insects only have one Treh1 and one Treh2 proteins, with only the coleopteran insects $T$. castaneum and $H$. axyridis having more than three soluble trehalase genes (Shi et al. 2016; Tang et al. 2014, 2016). In L. migratoria, it also has four trehalase genes, and a Treh2-like gene has been found, which is expressed in all tissues, such as integument, midgut, Malpighian tubules, fat body and so on. In addition, the expression levels of Treh1 and Treh2 in tissues are specific (Liu et al. 2016). In the same time, a Treh2-like gene was also found in $H$. axyridis in our study, and this is the first-found Treh2-like gene in insect.
We believe that trehalases are very important proteins and the Treh genes evolved through time; Treh2-like might represent the gene for a protein, intermediate in form, between the soluble and membrane-bound trehalases. Therefore, Treh2like could be a new class of trehalase genes, then more and more similar Treh2-like genes will be found.

The $\mathrm{pI}$ of soluble trehalases in insects is known to be around 4.5 and that of the membrane-bound forms is around 6.5 (Tang et al. 2012). However, pIs more than 6.5 have also been reported for some insect trehalases. It was reported that the $\mathrm{pI}$ of HaTreh1-3 was 8.88 and was similar to that of TcTreh1-2 (8.81), TcTreh1-3 (7.02), and DpTreh1-3 (6.56) (Shi et al. 2016; Tang et al. 2014). The pI of HaTreh1-5 has also been reported to be 9.20 and hence is positively charged, favoring adsorption onto the negatively charged matrix, also being higher than that of HaTreh1-4 (6.32), HaTreh2-like (5.52), and HaTreh2 (6.31). Almost all the insect trehalases have one signal peptide or putative cleavage 
Fig. 3 Expression levels of HaTreh1-5, HaTreh2-like, and HaTreh2 mRNAs relative to rp49 expression as measured using qRT-PCR. Each point represents the mean \pm SEM from three independent experiments. The developmental expression pattern of HaTreh1-5, HaTreh2like, and HaTreh2 cDNAs is represented. The indicated age of the insects is as follows: $4 \mathrm{~L} 1$, the first day of the fourth larva; 4L2, the second day of the fourth larva; 4L3, the third day of the fourth larva; 4L4, the fourth day of the fourth larva; PreP, pre-pupa which was the first stage of pupa; P-1, the first day of pupa; P-2, the second day of pupa; P-3, the third day of pupa; A-1, the first day of adult; A-2, the second day of adult, and A-3 the third day of adult
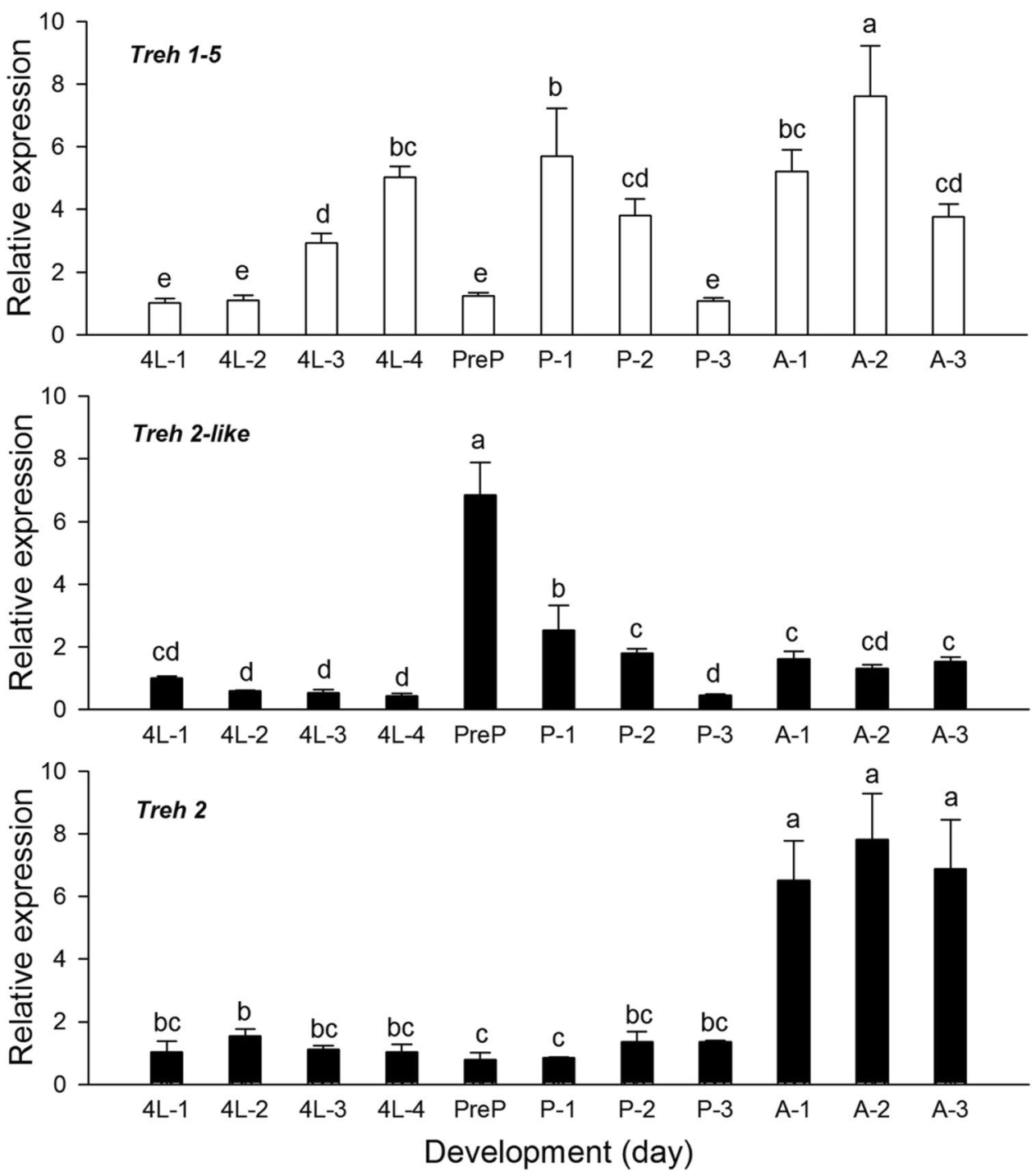

sites, ranging from 1 to 30 aa in length (Tang et al. 2012), an exception being AmTreh2 (NM_001112671) with a 35 aa signal peptide (Mori et al. 2009), while two Treh1 and one Treh2 in L. migratoria did not have the signal peptide structure (Liu et al. 2016). The signal peptide in the coleopterans contains about 20 aa, HaTreh1-1 to HaTreh1-4 have a 20- or 21-aa-long signal peptide, and HaTreh1-5 and HaTreh2 have signal peptides with 24 and 20 aa, respectively (Fig. S1A, C). It is interesting to note that HaTreh2-like did not have a signal peptide (Fig. S1B), this result is similar to L. migratoria Treh1 and Treh2 genes (Liu et al. 2016).

Many soluble insect trehalases were observed to be expressed in the midgut, fat body, epidermis, ovary, and Malpighian tubules of larvae in T. molitor (Gomez et al. 2013; Takiguchi et al. 1992), B. mori (Kamei et al. 2011; Kamimura et al. 1999), Pimpla hypochondriaca (Parkinson et al. 2003), as well as four soluble and one membranebound trehalases expressed in cuticle, fat body, midgut and
Malpighian tubules of the last larvae in T. castaneum (Tang et al. 2016). The expression of Treh1 and Treh2 in S. exigua was mainly observed in the last instar larvae, pupae, and adults (Chen et al. 2010). Most of the insects need two kinds of trehalases to use trehalose during the different developmental stages, but they only have one soluble and membrane-bound trehalase gene. However, $H$. axyridis has more than seven trehalase genes. Therefore, various trehalase genes play their specific functions at different stages of life. It can be found from the expression of five HaTreh1, one HaTreh2-like and one HaTreh2 during the development stages (Shi et al. 2016; Tang et al. 2014). HaTreh1-1 and HaTreh1-2 might play the role in the larval stage whereas HaTreh1-3 might have a role in stages from larva to adult (Tang et al. 2014). Moreover, HaTreh1-3, HaTreh1-5, and HaTreh2 are known to have roles in the adult stage (Fig. 3) (Shi et al. 2016). HaTreh2-like may also have a role during the pre-pupal stages (Fig. 3). In short, HaTreh1-5, 

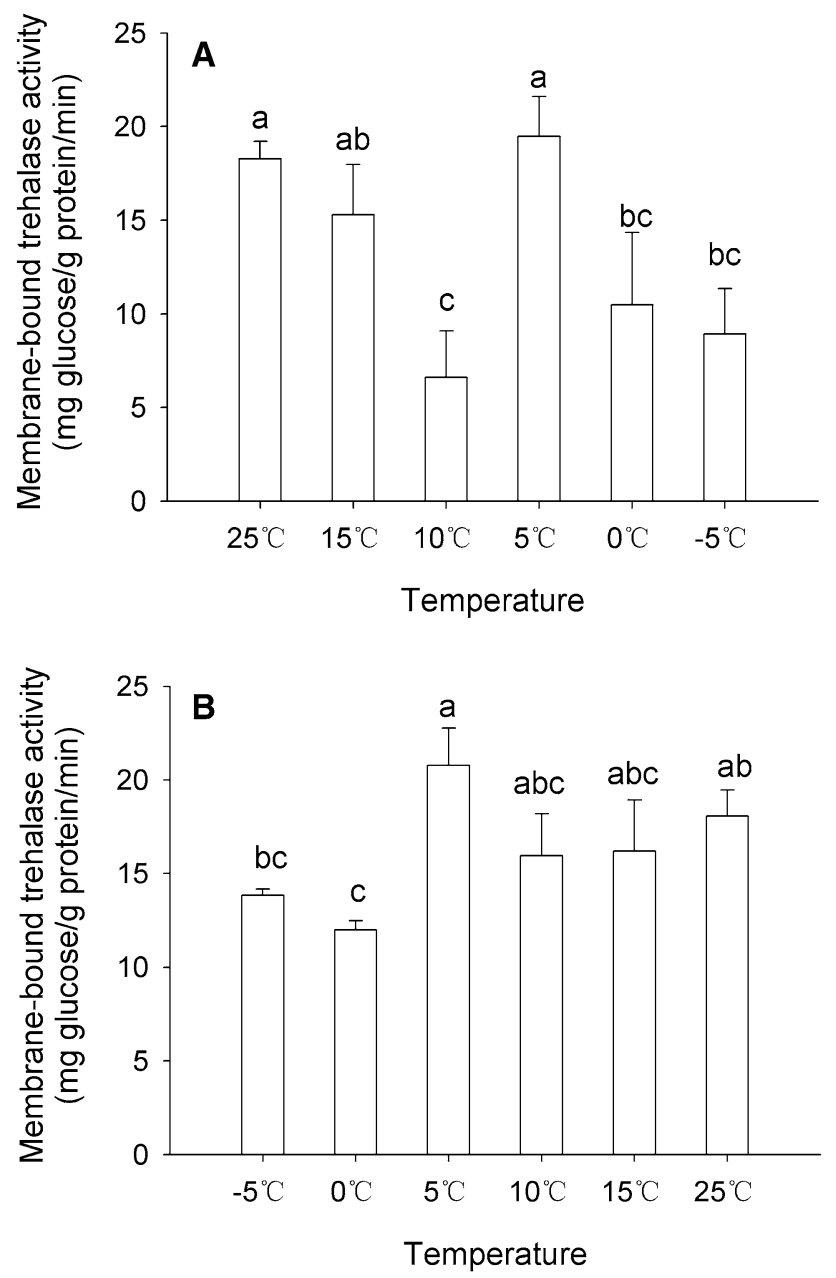

Fig. 4 Trehalase activities in H. axyridis during cooling (a) and warming (b) conditions. Membrane-bound trehalase activities were examined in (a) an environment that was gradually cooled from 25 to $-5{ }^{\circ} \mathrm{C}$ and (b) an environment that was gradually warmed from -5 to $25^{\circ} \mathrm{C}$. Bars with different letters indicate significant differences $(P<0.05)$. Data are presented as mean $\pm \mathrm{SD}(n=3)$

HaTreh2-like, and HaTreh2 have unique expression patterns through the developmental stages. These genes, including the other four HaTrehl genes, co-regulate the changes in the trehalose content and energy production to adapt to the development processes in $H$. axyridis.

Previous studies on the protective function of trehalose under different stress conditions, including desiccation, dehydration, heating, freezing, and oxidation, have been reported (Bale and Hayward 2010; Crowe et al. 1984; Elbein et al. 2003; Khani et al. 2007; Shimada 1984). In insects, trehalose participates in both the homeostasis and development as does the blood sugar (Silva et al. 2004; Thompson 2003); it is involved in processes such as flight metabolism, cold tolerance, and so on (Tatun et al. 2008a, b). In H. axyridis, the trehalose contents significantly increased when adults were placed at 5,0 , and $-5{ }^{\circ} \mathrm{C}$ during the cooling process (Shi et al. 2016), suggesting that it can protect $H$. axyridis from the cold stress, it was induced and as a cryoprotectant at $5{ }^{\circ} \mathrm{C}$ condition. A previous study showed that soluble trehalase activity could be gradually suppressed with the decrease in temperature (Shi et al. 2016). In the present study, we detected the membrane-bound trehalase activity (Treh2) during the cooling and warming processes. We observed that $5{ }^{\circ} \mathrm{C}$ was the turning point of the change of Treh2 activity, and the enzyme activity was the strongest at $5{ }^{\circ} \mathrm{C}$ (Fig. 4). Shi et al. found that trehalose content was the highest level at $5{ }^{\circ} \mathrm{C}$ during cooling process, it showed some sugars, such as glycogen, has transformed into trehalose (Shi et al. 2016). These results also indicate that a temperature of $5{ }^{\circ} \mathrm{C}$ may be critical for the adaptation of insects to cold; at this temperature, the insect not only requires more energy from trehalose, it also needs more trehalose for the coldresistance property of this sugar. For this reason, trehalases play an important role in insects transforming energy stored in different sugars. These results suggest that Treh2 activity plays a key role in the adaptation to the cooling process.

Trehalose-6-phosphate synthase gene expression has also been reported to increase from 25 to $5{ }^{\circ} \mathrm{C}$ during the cooling process (Qin et al. 2012). During the process of warming, the Treh1 activity showed an initial increase, followed by a decrease, and was increased again at $25^{\circ} \mathrm{C}$ (Shi et al. 2016). Treh2 activity was increased and was maintained at high levels throughout (Fig. 4b) in conjunction with a decrease in the trehalose content, signifying that Treh 2 might be playing a role in the warming process. However, the expression level of $T P S$, trehalose content and Treh activities increased when trehalase inhibitor of validamycin injected into $N$. lugens (Tang et al. 2017).

Trehalose is an energy source for insects providing energy for the movement and development of insects. It is rapidly used when the insect faces stress conditions (Tang et al. 2014; Thompson 2003). In contrast to cold acclimation during overwintering, which is induced over several weeks or months, rapid cold hardening of arthropods can be induced by a short exposure (several minutes or hours) to low temperatures (from 0 to $5{ }^{\circ} \mathrm{C}$ ) or through gradual cooling (from 0.1 to $1{ }^{\circ} \mathrm{C} \mathrm{min}^{-1}$ ) over a range of temperature (Lee et al. 1987; Lee 1991). The changes in the trehalase activity can be achieved through the modulation of the expressions of trehalase genes. For example, our results indicate that the relative expressions of Treh2-like and Treh 2 genes were consistent with changes in Treh2 activity during cooling (first decline, then increase at $5{ }^{\circ} \mathrm{C}$, then decrease). However, during the warming process, the trends between them were different, and we speculated that it may be related to other physiological processes not found in $H$. axyridis. In the present study, we observed changes in the expression of HaTreh1-5 and HaTreh2 mRNAs in the adults of H. axyridis subjected to rise and drop in temperature over a short period 

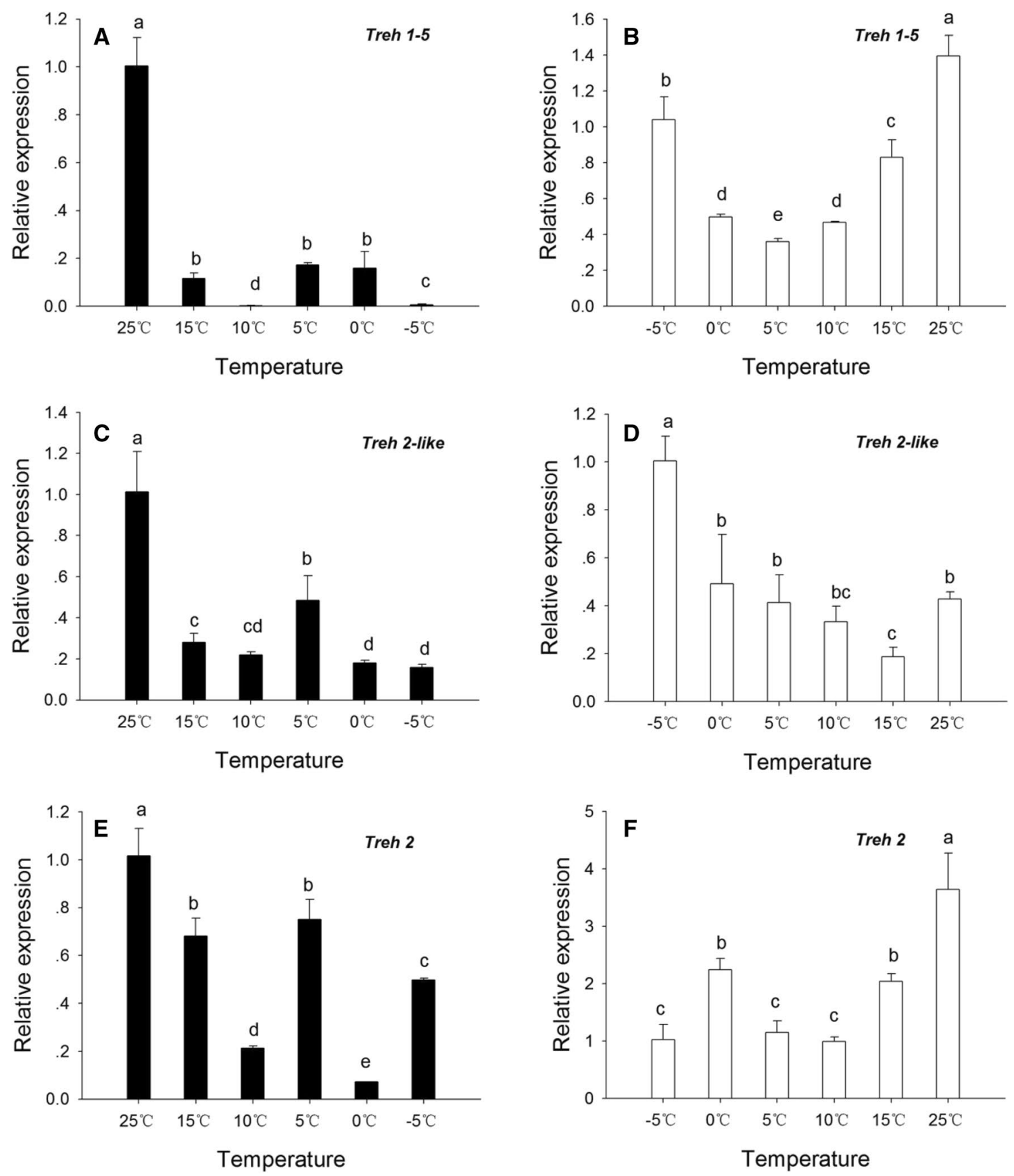

Fig. 5 Relative expression of HaTreh1-5 (a), HaTreh2-like (c), and HaTreh2 (e) identified from $H$. axyridis determined by real-time PCR in an environment gradually cooled from 25 to $-5{ }^{\circ} \mathrm{C}$. The relative expression of HaTreh 1-5 (b), HaTreh2-like (d), and HaTreh2 (f)

of time (Fig. 5). The expression of HaTrehl-4 has also been reported to decrease under cooling process (Shi et al. 2016) and the Treh1 activity was also observed to decrease. These results suggest that HaTreh1-4 and HaTreh1-5 play the main role during this process. HaTreh2-like and HaTreh2 could be sharing a similar function during the cooling process as revealed by their expression pattern and the Treh2 activity identified from $H$. axyridis were tested by real-time PCR in an environment gradually warmed from -5 to $25^{\circ} \mathrm{C}$. All the mRNA levels were measured relative to the $r p 49$ mRNA levels. Data are presented as mean $\pm \mathrm{SD}(n=3)$

(Figs. 4a, 5c, e). The expression of all the three HaTreh mRNAs showed a decreasing trend during the cooling process, indicating that all the Trehs play a protective role during low temperatures although the expression of those Treh genes are suppressed (Fig. 5). The expression of TPS mRNA has previously been shown to increase initially and then decease following the drop in temperature in $H$. axyridis 
adults (Qin et al. 2012). Moreover, higher TPS expression can increase the content of trehalose only if the activities of trehalase remain unchanged or decreased because of the decrease in Treh mRNA levels. It is also reported that the trehalose content increased when single TPS gene was knocked down (Tang et al. 2010; Yang et al. 2017). $H$. axyridis is an important predatory ladybug and a natural enemy of agricultural and forestry pests. It is very necessary to apply it to biological control, but low-temperature storage is a difficult problem. The results of Figs. 4 and 5 provide a theoretical basis for screening storage temperatures and the ability to improve resistance to low temperatures through cold training, such as $5{ }^{\circ} \mathrm{C}$ as a potential storage temperature. In addition, it seems that the rapid low-temperature stress of $H$. axyridis is more conducive to the accumulation of trehalose than the gradual cooling, because Treh2 activity has been maintained at a high level.

Trehalase is well known to be important in insect growth, development, and molting processes, and is involved in providing energy (Tang et al. 2008; Matsuda et al. 2015; Shukla et al. 2015; Yoshida et al. 2016). Moreover, the roles of different Trehl genes are not same, although the function of trehalases is to degrade trehalose to glucose (Tang et al. 2008; Chen et al. 2014; Shukla et al. 2015). The reason for the presence of more than five soluble trehalases, and a Treh2-like trehalase in some insects and understanding of their specific functions in development and growth, especially for tissue-specific distribution and its function on disaccharide-monosaccharide transition during different tissues at different time and conditions, would need further investigation.

\section{Conclusion}

Our study provides a theoretical basis for revealing the different physiological roles of three novel trehalase genes in the growth, cooling and re-warming process of $H$. axyridis. Results indicate that $H$. axyridis adults can accumulate trehalose early in the process of adaptation to rapid cold hardening. The physiological mechanisms underlying rapid cold hardening may also be associated with the accumulation of a cryoprotectant, such as glycerol and other low molecular weight polyhydric alcohols and sugars (Lee et al. 1987; Watanabe 2002; Zhao et al. 2008). The functional studies related to physiological adaption of insects having different HaTreh genes need to be undertaken in future. It should involve a combined approach in which the expression of Treh genes during the cooling or heating process is inhibited by RNA interference (RNAi) and the function of individual Treh genes is also knocked down by dsRNAs injection or by other methods.
Acknowledgements We thank the Regional First-class Discipline Construction of Guizhou Province (No. [2017]85), the Provincial Key and Special Subject of Guizhou Province-Ecology (No. ZDXK [2015]11) and Training Project for High-Level Innovative Talents in Guizhou Province (No. 2016 [4020]) for financial support.

\section{Compliance with ethical standards}

Conflict of interest The authors declare that the research was conducted in the absence of any commercial or financial relationships that could be construed as a potential conflict of interest.

Open Access This article is distributed under the terms of the Creative Commons Attribution 4.0 International License (http://creativeco mmons.org/licenses/by/4.0/), which permits unrestricted use, distribution, and reproduction in any medium, provided you give appropriate credit to the original author(s) and the source, provide a link to the Creative Commons license, and indicate if changes were made.

\section{References}

Adhav A, Harne S, Bhide A, Giri A, Gayathri P, Joshi R (2019) Mechanistic insights into enzymatic catalysis by trehalase from the insect gut endosymbiont Enterobacter cloacae. FEBS J 286(9):1700-1716

Adriaens T, Gomez GSM, Maes D (2008) Invasion history, habitat preferences and phenology of the invasive ladybird Harmonia axyridis in Belgium. Biocontrol 53(1):69-88

Bale J, Hayward S (2010) Insect overwintering in a changing climate. J Exp Biol 213(6):980-994

Bansal R, Mian MA, Mittapalli O, Michel AP (2013) Molecular characterization and expression analysis of soluble trehalase gene in Aphis glycines, a migratory pest of soybean. Bull Entomol Res 103(3):286-295

Bargiello TA, Grossfield J (1980) Electrophoretic purification of soluble trehalase from Drosophila melanogaster by selective unstacking. Anal Biochem 101(1):131-137

Bazzocchi GG, Lanzoni A, Accinelli G, Burgio G (2004) Overwintering, phenology and fecundity of Harmonia axyridis in comparison with native coccinellid species in Italy. Biocontrol 49(3):245-260

Berkvens N, Bale J, Berkvens D, Tirry L, De Clercq P (2010) Cold tolerance of the harlequin ladybird Harmonia axyridis in Europe. J Insect Physiol 56(4):438-444

Brown P, Adriaens T, Bathon H, Cuppen J, Goldarazena A, Hägg T, Kenis M, Klausnitzer BEM, Kovář I, Loomans AJM et al (2008a) Harmonia axyridis in Europe: spread and distribution of a nonnative coccinellid. Biocontrol 53(1):5-21

Brown PMJ, Roy HE, Rothery P, Roy DB, Ware RL, Majerus ME (2008b) Harmonia axyridis in Great Britain: analysis of the spread and distribution of a non-native coccinellid. Biocontrol 53:55-67

Caner S, Nguyen N, Aguda A, Zhang R, Pan YT, Withers SG, Brayer GD (2013) The structure of the Mycobacterium smegmatis trehalose synthase reveals an unusual active site configuration and acarbose-binding mode. Glycobiology 23(9):1075-1083

Chen J, Tang B, Chen HX, Yao Q, Huang XF, Chen J, Zhang DW, Zhang WQ (2010) Different functions of the insect soluble and membrane-bound trehalase genes in chitin biosynthesis revealed by RNA interference. PLoS One 5(4):e10133

Chen X, Quan Y, Wang H, Luo H (2014) Trehalase regulates neuroepithelial stem cell maintenance and differentiation in the Drosophila optic lobe. PLoS One 9(7):e101433 
Crowe J, Crowe L, Chapman D, Chapman D (1984) Preservation of membranes in anhydrobiotic organisms: the role of trehalose. Science 223(4637):701-703

Elbein AD, Pan YT, Pastuszak I, Carroll D (2003) New insights on trehalose: a multifunctional molecule. Glycobiology 13(4):17R-27R

Eleutherio EC, Araujo PS, Panek AD (1993) Role of the trehalose carrier in dehydration resistance of Saccharomyces cerevisiae. Biochim Biophys Acta 1156(3):263-266

Forcella M, Cardona F, Goti A, Parmeggiani C, Cipolla L, Gregori M, Schirone R, Fusi P, Parenti P (2010) A membrane-bound trehalase from Chironomus riparius larvae: purification and sensitivity to inhibition. Glycobiology 20(9):1186-1195

Frison M, Parrou JL, Guillaumot D, Masquelier D, Francois J, Chaumont F, Batoko H (2007) The Arabidopsis thaliana trehalase is a plasma membrane-bound enzyme with extracellular activity. FEBS Lett 581(21):4010-4016

Gomez A, Cardoso C, Genta FA, Terra WR, Ferreira C (2013) Active site characterization and molecular cloning of Tenebrio molitor midgut trehalase and comments on their insect homologs. Insect Biochem Mol Biol 43(8):768-780

Gu J, Shao Y, Zhang C, Liu Z, Zhang Y (2009) Characterization of putative soluble and membrane-bound trehalases in a hemipteran insect, Nilaparvata lugens. J Insect Physiol 55(11):997-1002

Heydari M, Izadi H (2014) Effects of seasonal acclimation on cold tolerance and biochemical status of the carob moth, Ectomyelois ceratoniae Zeller, last instar larvae. Bull Entomol Res 104(5):592-600

Huber RE, Lefebvre YA (1971) The purification and some properties of soluble trehalase and sucrase from Drosophila melanogaster. Can J Biochem 49(10):1155-1164

Kamei Y, Hasegawa Y, Niimi T, Yamashita O, Yaginuma T (2011) Trehalase-2 protein contributes to trehalase activity enhanced by diapause hormone in developing ovaries of the silkworm, Bombyx mori. J Insect Physiol 57(5):608-613

Kamimura M, Takahashi M, Tomita S, Fujiwara H, Kiuchi M (1999) Expression of ecdysone receptor isoforms and trehalase in the anterior silk gland of Bombyx mori during an extra larval molt and precocious pupation induced by 20-hydroxyecdysone administration. Arch Insect Biochem Physiol 41:79-88

Khani A, Moharramipour S, Barzegar M (2007) Cold tolerance and trehalose accumulation in overwintering larvae of the codling moth, Cydia pomonella (Lepidoptera: Tortricidae). Eur J Entomol 104(3):385-392

Koštál V, Miklas B, Doležal P, Rozsypal J, Zahradníčková H (2014) Physiology of cold tolerance in the bark beetle, Pityogenes chalcographus and its overwintering in spruce stands. J Insect Physiol 63:62-70

Lee RE (1991) Principles of insect low temperature tolerance. In: Lee RE, Denlinger DL (eds) Insects at low temperature. Chapman and Hall, New York, London, pp 17-46

Lee RE, Chen CP, Denlinger DL (1987) A rapid cold-hardening process in insects. Science 238(4832):1415-1417

Lee JH, Saito S, Mori H, Nishimoto M, Okuyama M, Kim D, Wongchawalit J, Kimura A, Chiba S (2007) Molecular cloning of cDNA for trehalase from the European honeybee, Apis mellifera L., and its heterologous expression in Pichia pastoris. Biosci Biotechnol Biochem 71(9):2256-2265

Liebl M, Nelius V, Kamp G, Ando O, Wegener G (2010) Fate and effects of the trehalase inhibitor trehazolin in the migratory locust (Locusta migratoria). J Insect Physiol 56(6):567-574

Liu XJ, Sun YW, Cui M, Ma EB, Zhang JZ (2016) Molecular characteristics and functional analysis of trehalase genes in Locusta migratoria. Sci Agric Sina 49(22):4375-4386
Livak KJ, Schmittgen TD (2001) Analysis of relative gene expression data using real-time quantitative PCR and the $2^{-\Delta \Delta \mathrm{Ct}}$ method. Methods 25(4):402-408

Luciana M, Nicolas D, Marina H, Marcela IS (2015) Intraguild predation between an exotic and a native coccinellid in Argentina: the role of prey density. J Pest Sci 88(1):155-162

Ma L, Dai W, Li XC, Zhang YL, Zhang CN (2015) Molecular cloning and expression analysis of soluble and membrane-bound trehalase genes in the cotton bollworm, Helicoverpa armigera. J Asia Pac Entomol 18(2):187-195

Matsuda H, Yamada T, Yoshida M, Nishimura T (2015) Flies without trehalose. J Biol Chem 290(2):1244-1255

Mitsumasu K, Azuma M, Niimi T, Yamashita O, Yaginuma T (2005) Membrane-penetrating trehalase from silkworm Bombyx mori. Molecular cloning and localization in larval midgut. Insect Mol Biol 14(5):501-508

Mori H, Lee JH, Okuyama M, Nishimoto M, Ohguchi M, Kim D, Kimura A, Chiba S (2009) Catalytic reaction mechanism based on alpha-secondary deuterium isotope effects in hydrolysis of trehalose by European honeybee trehalase. Biosci Biotechnol Biochem 73(11):2466-2473

Nardelli A, Vecchi M, Mandrioli M, Manicardi GC (2019) The evolutionary history and functional divergence of trehalase (treh) genes in insects. Front Physiol 10:62

Oliver MJ, Huber RE, Williamson JH (1978) Genetic and biochemical aspects of trehalase from Drosophila melanogaster. Biochem Genet 16(9-10):927-940

Parkinson NM, Conyers CM, Keen JN, MacNicoll AD, Smith I, Weaver RJ (2003) cDNAs encoding large venom proteins from the parasitoid wasp Pimpla hypochondriaca identified by random sequence analysis. Comp Biochem Physiol 134(4):513-520

Pervez A, Omkar (2006) Ecology and biological control application of multicoloured Asian ladybird, Harmonia axyridis: a review. Biocontrol Sci Technol 16(2):111-128

Qin Z, Wang S, Wei P, Xu CD, Tang B, Zhang F (2012) Molecular cloning and expression in cold induction of trehalose-6-phosphate synthase gene in Harmonia axyridis (Pallas). Acta Entomol Sin 55(6):651-658

Shi ZK, Liu XJ, Xu QY, Qin Z, Wang S, Zhang F, Wang SG, Tang B (2016) Two novel soluble trehalase genes cloned from Harmonia axyridis and regulation of the enzyme in a rapid changing temperature. Comp Biochem Physiol 198:10-18

Shimada K (1984) Seasonal changes of glycogen/trehalose contents, super cooling point and survival rate in mature larvae of the overwintering soybean pod borer, Leguminivora glycinivorella. J Insect Physiol 30:369-373

Shukla E, Thorat LJ, Nath BB, Gaikwad SM (2015) Insect trehalase: physiological significance and potential applications. Glycobiology 25(4):357-367

Shukla E, Thorat L, Bhavnani V, Bendre AD, Pal JK, Nath BB, Gaikwad SM (2016) Molecular cloning and in silico studies of physiologically significant trehalase from Drosophila melanogaster. Int J Biol Macromol 92:282-292

Shukla E, Thorat L, Bendre AD, Jadhav S, Pal JK, Nath BB, Gaikwad SM (2019) Cloning and characterization of trehalase: a conserved glycosidase from oriental midge, Chironomus ramosus. 3 Biotech 8(8):352

Silva CPM, Terra RW, Ferreira C (2004) The role of carboxyl, guanidine and imidazole groups in catalysis by a midgut trehalase purified from an insect larvae. Insect Biochem Mol Biol 34(10):1089-1099

Silva MC, Terra WR, Ferreira C (2010) The catalytic and other residues essential for the activity of the midgut trehalase from Spodoptera frugiperda. Insect Biochem Mol Biol 40(10):733-741

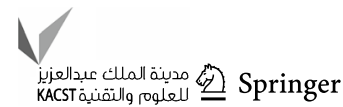


Suann M, Bogema DR, Chen YZ, Mansfield S, Barchia IM, Herron G (2015) A TaqMan qPCR method for detecting kdr resistance in Aphis gossypii demonstrates improved sensitivity compared to conventional PCR-RFLP. J Pest Sci 88(4):785-791

Takiguchi M, Niim T, Su ZH, Yaginuma T (1992) Trehalase from male accessory gland of an insect, Tenebrio molitor. cDNA sequencing and developmental profile of the gene expression. Biochem J 288(1):19-22

Tang B, Chen XF, Liu Y, Tian HG, Liu J, Hu J, Xu WH, Zhang WQ (2008) Characterization and expression patterns of a membranebound trehalase from Spodoptera exigua. BMC Mol Biol 9:51

Tang B, Chen J, Yao Q, Pan ZQ, Xu WH, Wang SG, Zhang WQ (2010) Characterization of a trehalose-6-phosphate synthase gene from Spodoptera exigua and its function identification through RNA interference. J Insect Physiol 56(7):813-821

Tang B, Wei P, Chen J, Wang SG, Zhang WQ (2012) Progress in gene features and functions of insect trehalases. Acta Entomol Sin 55:1315-1321

Tang B, Qin Z, Shi ZK, Wang S, Guo XJ, Wang SG, Zhang F (2014) Trehalase in Harmonia axyridis (Coleoptera: Coccinellidae): effects on beetle locomotory activity and the correlation with trehalose metabolism under starvation conditions. Appl Entomol Zool 49(2):255-264

Tang B, Wei P, Zhao LN, Shi ZK, Shen QD, Yang MM, Xie GQ, Wang SG (2016) Knockdown of five trehalase genes using RNA interference regulates the gene expression of the chitin biosynthesis pathways in Tribolium castaneum. BMC Biotechnol 16(1):67

Tang B, Yang MM, Shen QD, Wang HJ, Wang SG (2017) Suppressing the activity of trehalase with validamycin disrupts the trehalose and chitin biosynthesis pathways in rice brown planthopper, Nilaparvata lugens. Pestic Biochem Physiol 137:81-90

Tang B, Wang S, Wang SG, Wang HJ, Zhang JY, Cui SY (2018) Invertebrate trehalose-6-phosphate synthase gene: genetic architecture, biochemistry, physiological function, and potential applications. Front Physiol 9:30

Tatun N, Singtripop T, Sakurai S (2008a) Dual control of midgut trehalase activity by 20 -hydroxyecdysone and an inhibitory factor in the bamboo borer Omphisa fuscidentalis Hampson. J Insect Physiol 54(2):351-357

Tatun N, Singtripop T, Tungjitwitayakul J, Sakurai S (2008b) Regulation of soluble and membrane-bound trehalase activity and expression of the enzyme in the larval midgut of the bamboo borer Omphisa fuscidentalis. Insect Biochem Mol Biol 38(8):788-795

Terblanche JS, Hoffmann AA, Mitchell KA, Rako L, le Roux PC, Chown SL (2011) Ecologically relevant measures of tolerance to potentially lethal temperatures. J Exp Biol 214(Pt22):3713-3725

Thompson SN (2003) Trehalose- the insect 'blood' sugar. Adv Insect Physiol 31:203-285

Valaitis AP, Bowers DF (1993) Purification and properties of the soluble midgut trehalase from the gypsy moth, Lymantria dispar. Insect Biochem Mol Biol 23:599-606 van Lenteren JC, Loomans AJ, Babendreier D, Bigler F (2008) Harmonia axyridis: an environmental risk assessment for Northwest Europe. Biocontrol 53:37-54

van Wyk N, Drancourt M, Henrissat B, Kremer L (2017) Current perspectives on the families of glycoside hydrolases of Mycobacterium tuberculosis: their importance and prospects for assigning function to unknowns. Glycobiology 27(2):112-122

Wang HJ, Shi ZK, Shen QD, Xu CD, Wang B, Meng ZJ, Wang SG, Tang B, Wang S (2017) Molecular cloning and induced expression of six small heat shock proteins mediating cold-hardiness in Harmonia axyridis (Coleoptera: Coccinellidae). Front Physiol 8:60

Watanabe M (2002) Cold tolerance and myo-inositol accumulation in overwintering adults of a lady beetle, Harmonia axyridis (Coleoptera: Coccinellidae). Eur J Entomol 99:5-10

Wingler A (2002) The function of trehalose biosynthesis in plants. Phytochemistry 60:437-440

Wu MJ, Xu QY, Liu Y, Shi XR, Shen QD, Yang MM, Wang SG, Tang B (2016) The supercooling point change of Harmonia axyrids under low temperature stress and its cold-resistance genes' expression analysis. Sci Agric Sina 49:677-685

Xu J, Bao B, Zhang ZF, Yi YZ, Xu WH (2009) Identification of a novel gene encoding the trehalose phosphate synthase in the cotton bollworm, Helicoverpa armigera. Glycobiology 19(3):250-257

Yaginuma T, Mizuno T, Mizuno C, Ikeda M, Wadam T, Hattorim K, Yamashita O, Happ GM (1996) Trehalase in the spermatophore from the bean-shaped accessory gland of the male mealworm beetle, Tenebrio molitor: purification, kinetic properties and localization of the enzyme. J Comp Physiol B 166:1-10

Yang MM, Zhao LN, Shen QD, Xie GQ, Wang SG, Tang B (2017) Knockdown of two trehalose-6-phosphate synthases severely affects chitin metabolism gene expression in the rice brown planthopper Nilaparvata lugens. Pest Manag Sci 73:206-216

Yoshida M, Matsuda H, Kubo H, Nishimura T (2016) Molecular characterization of Tpsl and Treh genes in Drosophila and their role in body water homeostasis. Sci Rep 6:30582

Zappalà L, Biondi A, Alma A, Al-Jboory IJ, Arnò J, Bayram A, Chailleux A, El-Arnaouty A, Gerling D, Guenaoui Y et al (2013) Natural enemies of the South American moth, Tuta absoluta, in Europe, North Africa and Middle East, and their potential use in pest control strategies. J Pest Sci 86:635-647

Zhang Q, Lu DH, Pu J, Wu M, Han ZJ (2012) Cloning and RNA interference effects of trehalase genes in Laodelphax striatellus (Homoptera: Delphacidae). Acta Entomol Sin 55:911-920

Zhao J, Yu LY, Li M, Zheng FQ, Zhang F, Xu YY (2008) Seasonal variation in cold tolerance of the multicolored ladybeetle, Harmonia axyridis (Pallas) (Coleoptera: Coccinellidae) adults. Acta Entomol Sin 51:1271-1278

Zhao LN, Yang MM, Shen QD, Liu XJ, Shi ZK, Wang SG, Tang B (2016) Functional characterization of three trehalase genes regulating the chitin metabolism pathway in rice brown planthopper using RNA interference. Sci Rep 6:27841 